\title{
O Programa Nacional de Solidariedade: fatos e idéias em torno de um esforço
}

\section{CARLOS ROJAS GUTIÉRREZ}

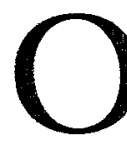

Programa Nacional de Solidariedade (Pronasol) tem suas origens nas formas de trabalho empregadas pelos mexicanos para fazer frente a seus problemas vitais.

Algumas instituições solidárias conservaram seu modelo tradicional, enquanto outras adotaram novas formas de organizaçăo. Formas tradicionais de execução de tarefas e prestação de serviços, bem como comitês de eletrificação, juntas de vizinhos ou de pais de família são exemplos, entre tantos outros, da cooperação voluntária para alcançar metas que tragam benefícios ao indivíduo e à comunidade, reforçandose os laços de unidade, segurança e reciprocidade na ajuda e proteção conjuntas.

A solidariedade supera qualquer esforço isolado dos setores da sociedade; a unidade e participação de todos é o maior recurso do país diante das urgentes necessidades daqueles que não contam com o menor bem-estar e frente aos desafios do mundo contemporâneo.

O Governo da República reconhece sua importância e vigência, ao recuperá-la como essência do Programa, e ao recolhê-la das práticas cotidianas das comunidades rurais e das colônias.

Recuperou-se também o aspecto positivo das experiências obtidas em programas anteriores - produtivos e de bem-estar - tais como o Programa para o Desenvolvimento Rural Integral (PIDER) e a Comissão do Plano Nacional para o Atendimento às Zonas Deprimidas e aos Grupos Marginalizados (Coplamar).

Os objetivos

Grande número de mexicanos vive em condiçóes de pobreza no 
campo e nas cidades. Suas necessidades básicas não estão adequadamente satisfeitas, e têm deficiências em nutrição, saúde, educação, habitação, ambiente, acesso aos serviços públicos e emprego produtivo.

Aqueles que não satisfazem os requisitos mínimos de bem-estar sáo produtores de poucos recursos, baixa produtividade e posição frágil para reter parte significativa do valor que geram com seu trabalho. Distribuem-se desarticuladamente nas zonas áridas, em terras de baixo rendimento e alto risco, assim como nos espaços desprotegidos das cidades.

As causas da pobreza são múltiplas e complexas. Por isso, as açóes do Programa em todo o país são organizadas conforme as prioridades definidas pelas comunidades

Os povos indígenas têm prioridade especial porque se encontram em condiçóes de extrema pobreza, injustiça, marginalizaçáo e desvantagem (1).

Os camponeses e habitantes do meio rural nas áreas semidesertas e montanhosas vivem seriamente afetados pela incerteza dos obstáculos de seu contexto. $O$ investimento produtivo e os serviços năo tiveram o efeito esperado e persistem as precariedades e limitaçóes. Dessas zonas emigram muitos mexicanos em busca de melhores oportunidades. Os trabalhadores rurais migrantes assentam-se temporariamente nas regióes agrícolas mais produtivas sem, contudo, deixar de viver em condiçóes de pobreza.

Nas metrópoles e nas médias e pequenas cidades do país registrouse crescimento acelerado das colônias, apesar de seu assentamento irregular, inexistência de serviços e dificuldades na obtenção de emprego e receita estável.

Os jovens também se ressentem da pobreza e da falta de oportunidades; muitos se formaram para uma alternativa de mobilidade não ocorrida. Não é possível que sua capacidade e força sejam desperdiçadas.

As mulheres são duplamente afetadas pela pobreza; seus esforços se direcionam cada vez mais a uma atividade econômica, além de serem responsáveis pelo cuidado com os filhos e pelo lar.

O Pronasol tenta romper o círculo vicioso que reproduz e aumenta a pobreza de uma geração para outra. Alimentação, saúde e educação são fundamentais para o desenvolvimento harmonioso das faculdades humanas; e as crianças sáo prioridade indiscutível para a naçăo, porque nelas se apóia o futuro do país. 
A pobreza se manifesta em todo o território, mas concentra-se em áreas e grupos populacionais delimitados. Em algumas entidades é a condição social predominante, razão por que, para elas, a atenção é sistemática e de acordo com clara ordem de prioridades.

A resposta social que o Pronasol encontra para combater a pobreza desde as causas que a originam, até suas conseqüências, baseia-se em três propósitos fundamentais:

- Solidariedade para o bem-estar social: melhoria imediata dos níveis de vida, com ênfase nos aspectos de saúde, alimentaçáo, educação, habitação, serviços básicos e posse da terra.

- Solidariedade para a produção: oportunidades de emprego e desenvolvimento das capacidades e recursos produtivos, com apoio às atividades agropecuárias, agroindustriais, microindustriais e de piscicultura.

- Solidariedade para o desenvolvimento regional: construçáo de obras de infra-estrutura com repercussão regional e execução de programas de desenvolvimento em regiōes específicas.

O Programa cria real sustentaçáo produtiva para a melhoria do nível de vida. Somente com participação direta e trabalho produtivo que incrementem a receita familiar serăo melhorados os níveis de bem-estar dos indígenas, dos camponeses e dos colonos, possibilitando a erradicação a pobreza no México.

\section{Uma nova forma de fazer as coisas}

O Pronasol tem, em todas as suas ações e projetos, quatro princípios fundamentais.

- Respeito a pontade, iniciatipas e formas de organizacão dos individuos $e$ de suas comunidades. O Programa convoca, articula e apóia pedidos e iniciativas de solução, não impõe decisóes nem estabelece clientelismos ou condiçôes. As organizaçóes adotam estratégias e métodos de trabalho próprios nos projetos e ações. A diversidade do país e das formas de organização comunitária refletem-se fielmente no programa.

- Plena e efetiva participação e organização em todas as açóes do Programa.A participação é exercida em planejamento, tomada de decisões, acompanhamento, controle e avaliação dos projetos combinados com indivíduos e organizaçóes. A participaçáo também se expressa em trabalho direto, contribuição com recursos e materiais próprios da região, e em um manejo controlado, que beneficie realmente 
aqueles que mais necessitam, funcionando como eficaz controle social.

- Co-responsabilidade. Todos os projetos são definidos em convênios nos quais são especificados contribuiçóes, responsabilidades e compromissos das partes. As obrigaçóes aceitas são executadas com a unidade de recursos e vontades expressas publicamente, com base na confiança e na colaboração.

- Transparéncia, honestidade e eficiéncia na administrafão dos recursos. Os recursos do Programa são da nação. Seu uso deve ser escrupulosamente honesto, transparente e público, mediante a intervenção das comunidades em seu manejo, vigilância e avaliação de resultados. Deve ser gerido de forma ágil, simples e oportuna, sem burocracia ou centralização. A transparência e a eficiência baseiam-se em decisões e ações dirigidas pelas comunidades.

Com esses quatro princípios elimina-se qualquer vestígio de populismo, condicionamento político ou simulação na melhoria produtiva do nível de vida da populaçáo em estado de pobreza. O Solidariedade é de todos os mexicanos, náo representa a frustraçáo dos ideais de cada um. O Programa impulsiona a mobilização social para os indivíduos trabalharem unidos pelo progresso dos que têm menos; este é o acordo fundamental que permite atingir consenso plural por desenvolvimento e justiça social.

\section{Estrutura e organização do Programa}

A Comissão do Programa Nacional de Solidariedade é o órgão encarregado de coordenar e definir as políticas, estratégias e ações empreendidas no âmbito da administraçáo pública para combater os baixos níveis de vida e assegurar o cumprimento dos programas especiais objetivando atendimento aos núcleos indígenas e à população das zonas áridas e urbanas em termos de saúde, educação, alimentaçăo, habitação, emprego e projetos produtivos.

No Conselho Consultrvo da Comissão expressam-se opiniōes e propostas orientadas para definir e aperfeiçoar as bases do ajuste nos programas dirigidos pela Comissão.

Conta-se também com um Comitê de Avaliação, que pesquisa o efeito social e econômico dos programas realizados.

A Coordenação Geral do Programa participa do estabelecimento das bases para a assinatura dos Convênios Únicos de Desenvolvimento que o Presidente da República assina com cada um dos governadores 
dos Estados, formalizando acordos e compromissos conjuntos de investimento.

Nos convênios é determinada parte específica para o Solidariedade a fim de, no interior dos Comitês de Planejamento do Desenvolvimento

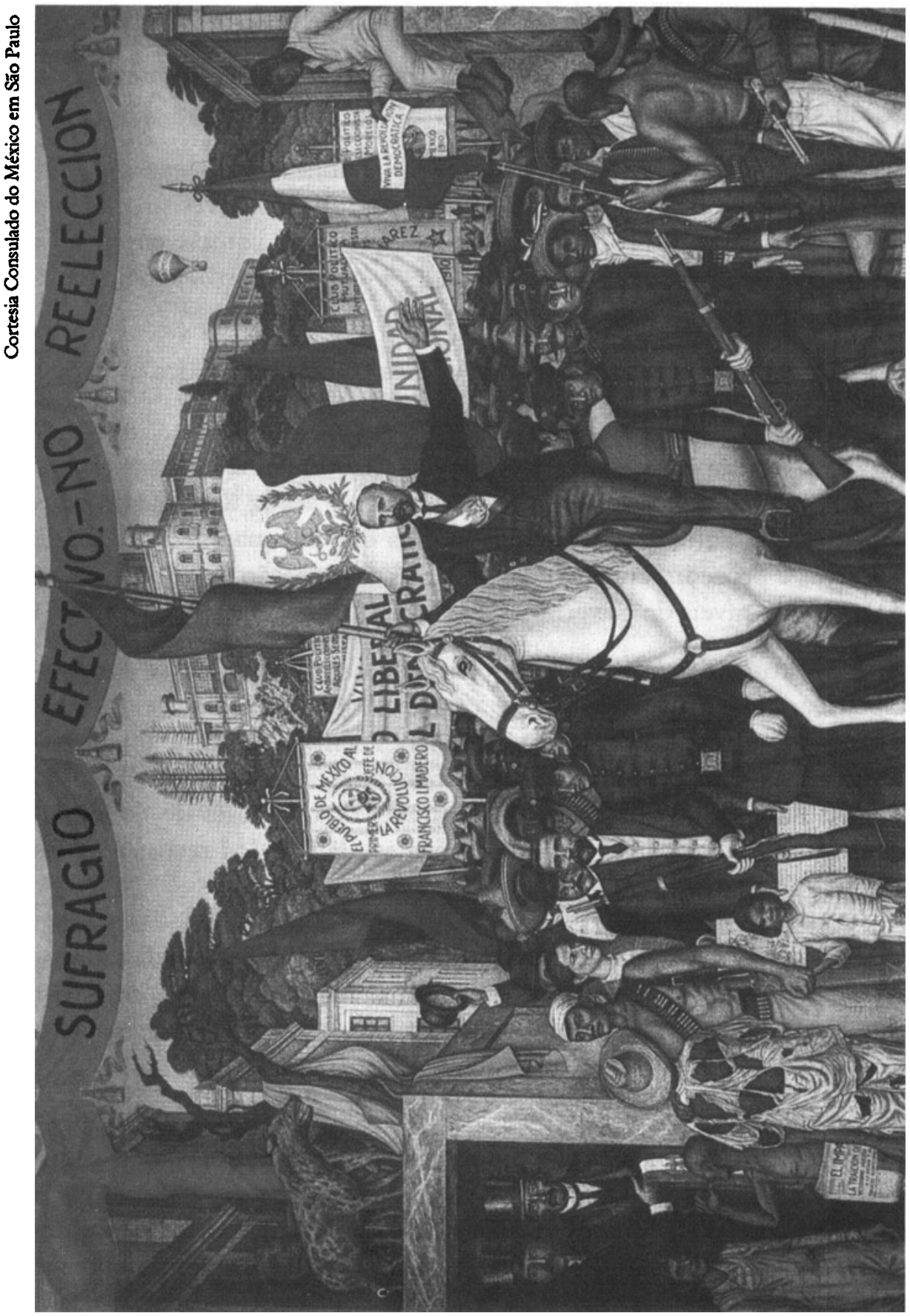


dos estados, reunir as autoridades dos governos federal, estadual e municipal, para definir, controlar e avaliar os projetos produtivos e as obras de infra-estrutura e bem-estar social, dos quais participam ativamente as comunidades, mediante os Comitês de Solidariedade.

Esses comitês promovem a organizaçăo dos povos indígenas, camponeses e colonos populares para coletar experiências, tradiçōes e valores desenvolvidos pelas comunidades. Assim adquirem as formas e denominações que melhor respondem às peculiaridades culturais de cada região e localidade.

Os comitês, eleitos em assembléias públicas pelo exercício da democracia direta, coordenam-se com as autoridades governamentais e com os demais setores sociais, definindo o que fazer, como e em quanto tempo, a que custo, com que qualidade, e como seráo recuperados e reinvestidos os apoios financeiros obtidos.

Os comitês exercem autêntico controle social $\mathrm{em}$ todas as etapas dos projetos produtivos e nas obras de bem-estar.

Um dos aspectos a ser destacado na estrutura e na organizaçáo do Programa é o de não se criarem organismos burocráticos; aproveitam-se as entidades e estruturas já existentes (2), as que adequaram algumas de suas áreas e procedimentos para agilizar a coordenação entre as instituiçóes dos três níveis de governo.

O esforço de coordenação é desenvolvido observando-se o estrito respeito ao limite legal aplicável e a normatividade reguladora do exercício e do controle do orçamento público. Além do controle que legalmente têm sob sua responsabilidade a Secogef e a Secretaria Geral da Fazenda da Câmara dos Deputados, através dos Comitês de Solidariedade estimula-se a participaçáo social na vigilância dos recursos e das obras.

Dessa forma eliminam-se o paternalismo e a dependência na relaçáo entre sociedade e governo; conjugam-se idéias e esforços em favor da unidade e do progresso, que só são construídos com o consenso e o trabalho co-responsável de todos.

\section{Uma mudança profunda nos negócios públicos}

As açóes do Pronasol constituem o eixo articulador da política social e fazem parte da modernização nacional que configura a reforma do Estado. 
O Programa inclui todos os setores da sociedade no desafio de erradicar a pobreza; é tarefa de toda a nação nos âmbitos econômico, social, político e cultural.

A certeza de ser esse o caminho para melhorar as condiçóes de vida daqueles que mais necessitam motivou profunda mudança na forma de realizar as ações do governo. Trata-se de mudança que recupera o fundamental: a participação co-responsável da sociedade organizada e das instituições públicas, centrando-se no município autônomo, base da divisão política e administrativa da República.

\section{A democracia direta nas comunidades}

Tende-se a dar denominação comum à forma de organização das comunidades participantes: os Comitês de Solidariedade. Estes formam o espaço onde se coordena a gestão social, lugar em que se exprime diretamente a vontade popular. Regularmente, os comitês têm como participantes: presidente, secretário, tesoureiro, vogal de controle e vigilância e vogais adicionais com responsabilidade específica eleita por decisão da comunidade.

Os comitês promovem a participação social; convocam a assembléia para analisar assuntos de interesse comum e decidir as características dos projetos que se espera realizar; coordenam os trabalhos e as contribuiçóes com que se comprometeram os membros da comunidade, e zelam pelo cumprimento dos compromissos assumidos.

O Solidariedade tem claro sentido político de igualdade e justiça social, porém isso não significa que tenha filiação partidária. Não se condiciona a qualquer comunidade, nem exige dela compromisso ideológico; trabalha da mesma forma nos municípios governados pelo partido no poder, como pelos da oposiçáo.

O Solidariedade tampouco atende a fins eleitorais ou de curto prazo. As açóes para criar empregos e desenvolver recursos e capacidades produtivas das comunidades e dos indivíduos são dirigidas às causas que os mantinham marginalizados do progresso. As obras sociais priorizadas pelas comunidades realizam-se com sua participaçáo e controle direto. $O$ benefício é real, permanece nas comunidades, para o bem-estar de seus filhos e das futuras geraçóes.

O Programa converteu-se em espaço para o exercício da liberdade e da democracia. A diversidade e a pluralidade são expressas na participação, e a concordância é sua ferramenta; incentiva-se a crítica e o diálo- 
go tolerante e respeitoso. Contribui-se, em síntese, para o desenvolvimento da cultura política do país.

\section{A somatória de esforços institucionais}

Para o Solidariedade confluem, a partir de seus respectivos âmbitos de competência, todas as dependências e entidades da administração pública em seus três níveis de governo. Trata-se de um esforço de coordenação sem precedentes, em torno de tarefa da mais alta prioridade.

Os convênios únicos de desenvolvimento planejam e coordenam as ações para estender os benefícios do Programa a todos os municípios do país.

A administração municipal é a instância que permitiu ao Programa ter proximidade real com a populaçăo, e responder efetivamente a suas necessidades e projetos de solução.

Respeitam-se os âmbitos de ação e os representantes legais das entidades federativas para responder às particularidades de cada regiāo e localidade, aproveitando recursos e potencialidade de cada uma delas.

\section{Um programa descentralizado}

Desde seu início o Programa descentralizou açóes e recursos nos governos estaduais e municipais, e nas comunidades participantes. As decisóes são tomadas e os recursos aplicados onde existem problemas, pelos encarregados de pôr as soluções em prática.

A administraf̧̃o municipal é apoiada para ser a instância de coordenação; quando as características técnicas demandam processos financeiros ou técnicos mais complexos, procura-se o apoio do governo estadual para os projetos. $O$ governo federal contribui quando solicitado pelos governos estadual ou municipal, mas o faz enquanto entidade normativa e para efeitos de assessoria ou apoio específico.

A descentralização permite que decisóes, movimentação dos recursos, execução e controle das açóes estejam diretamente relacionados com a população, em contexto de cooperaçáo e responsabilidade compartilhadas.

\section{Um programa municipalista}

O Solidariedade torna realidade as reformas constitucionais orien- 
tadas para fortalecer o município autônomo. As administraçóes municipais são constituídas por vizinhos das comunidades que conhecem $\mathrm{e}$ compartilham seus problemas, sendo instância idônea para coordenar esforços sociais e institucionais contra a pobreza.

A administração municipal tem importante participação na operação dos programas do Solidariedade; é o caso de Solidariedade para uma Escola Digna; Crianças em Solidariedade; Mulheres em Solidariedade;

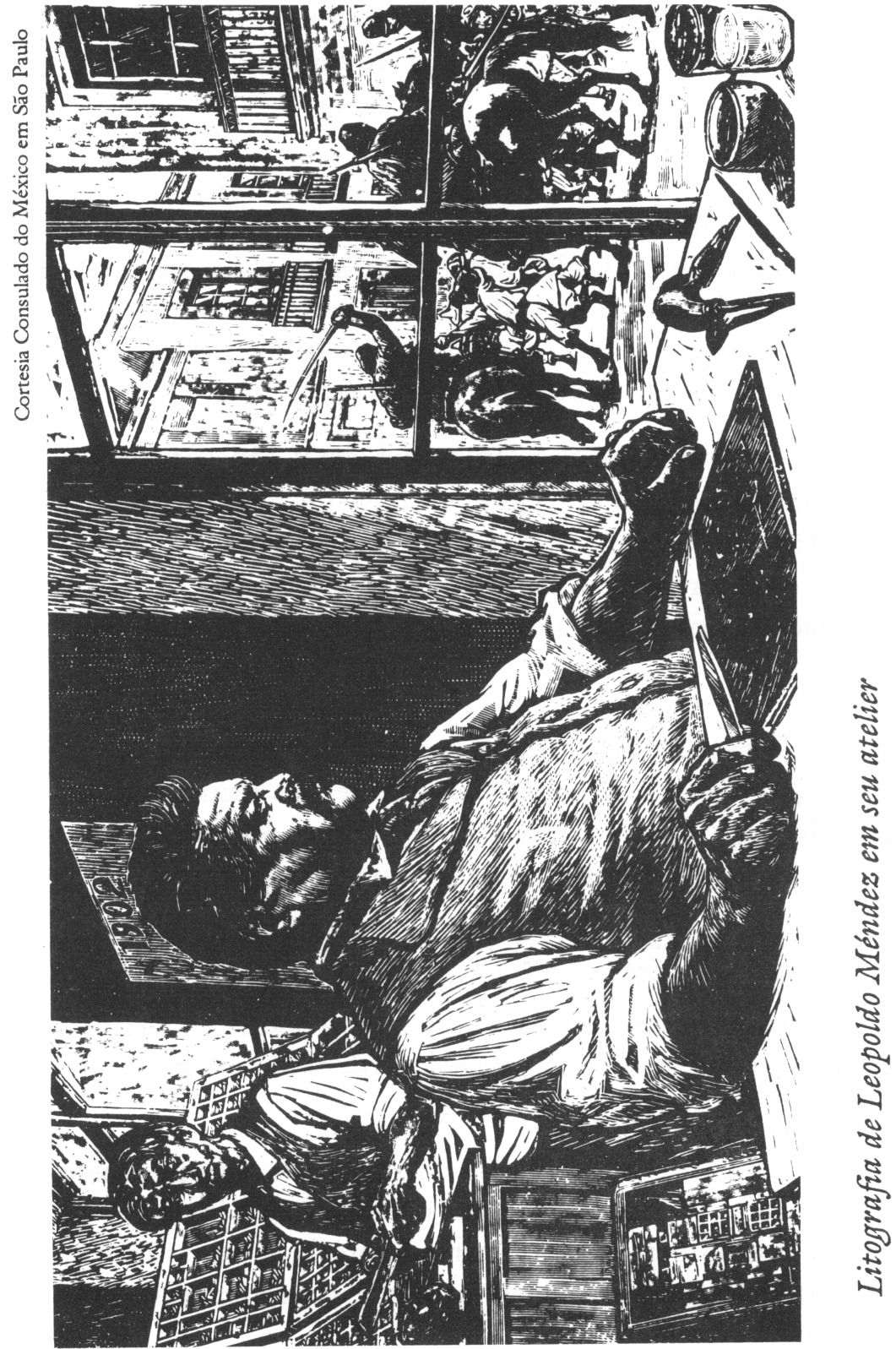


Fundos de Solidariedade para a Produfaro; Programas para Comunidades Indigenas; Fundos Municipais de Solidariedade; os Comitts de Solidariedade para a introdufáo dos servifos bdsicos, como a urbanizaçáo, melhoria da habitaçáo etc.

Os municípios estabelecem contato direto e permanente com suas comunidades para definir quais obras sociais realizar, seu custo, calendário de execução e controle de qualidade adequado. Quanto aos fundos de apoio, define-se a quem será concedido financiamento e as formas de retorno para que novos investimentos sejam feitos em outras áreas de benefício comum; assim se consegue ampliar e estender os recursos disponíveis, os quais se multiplicam com o passar do tempo.

\section{Os recursos}

O Solidariedade se traduz por um conjunto de projetos de investimento financiados com diversificadas fontes, entre as quais contribuiçóes diretas dos indivíduos, em forma de trabalho, materiais, infraestrutura disponível e reparos. Com a colaboraçáo acertada livremente entre sociedade e governo, ampliam-se os meios de combate à pobreza.

Os recursos destinados pelo orçamento federal são o principal componente de financiamento do Programa. Os custos operacionais das instituiçóes públicas participantes são cobertos por seus orçamentos ordinários. Assim, os recursos destinados ao Programa aplicam-se totalmente nas prioridades e nos grupos de populaçáo que se deliberou beneficiar.

Os governos estaduais e municipais canalizam também importantes dotaçōes orçamentárias. Embora insuficientes, os recursos destinados até agora náo têm precedentes na história recente do país; tomouse a firme decisáo de incrementá-los ao longo do atual regime.

O Programa não causa qualquer pressão inflacionária motivada por expansáo monetária, déficit fiscal ou excessivo gasto público. Somam-se os recursos programados para o bem-estar social $e o$ aprimoramento produtivo, com um plano ágil de coordenaçáo entre os três níveis de governo e as entidades paraestatais.

A erradicação da pobreza é demanda da sociedade, compromisso histórico e necessidade da modernizaçáo nacional. Ainda que seja impossível eliminá-la totalmente em um período presidencial, as bases e os meios para a transformaçáo de suas causas e conseqüências mais graves ficarăo firmemente alicerçadas. 


\section{Alguns progressos de destaque e projeção}

Os avanços mais significativos do Pronasol são melhor observados na convivência direta com as comunidades organizadas que executam os projetos produtivos e de bem-estar. É na nova atitude e relação entre sociedade e governo que se aprecia com maior clareza o impulso que o esforço pela justiça social está tomando no México.

Os dados apresentados a seguir, de forma breve e genérica, são apenas amostra descritiva do que já se conseguiu quantitativamente (3).

Em termos de saúde, deu-se maior prioridade a seu atendimento, para compensar efeitos mais graves da crise e criar infra-estrutura social demandada pelas comunidades sem acesso a esse tipo de serviço ou aos medicamentos básicos.

Em todas as unidades médicas a populaçáo colabora com o pessoal médico e de enfermagem, por meio dos Comités de Solidariedade para a Saúde, capacitando a população em planejamento familiar e nutriçăo e realizando campanhas de vacinaçáo da população infantil. Os médicos que prestam serviço social nessas unidades participam da distribuição de pacotes de sementes para o cultivo de hortas familiares, e assessoram a população na construção de albergues comunitários, para acolher temporariamente os familiares dos doentes que precisam de hospitalização.

Para elevar a qualidade, a humanização dos serviços de saúde, e para preservar a infra-estrutura existente, em 1991 foi criado o Programa de Solidariedade para um Hospital Digno, a cargo dos governos estaduais e das autoridades que integram o setor. Com a participaçáo do pessoal médico e das comunidades, organizam-se Comitês de Solidariedade nos hospitais materno-infantis, gerais, civis, psiquiátricos e de especialidades e nos institutos.

A magnitude e a dinâmica de crescimento populacional, assim como sua dispersão no meio rural, representam desafio para a cobertura do sistema educativo nacional. Desafio adicional consiste em elevar a qualidade e a eficiência final da educação, especialmente na primária. O Solidariedade deu prioridade à educação nesse nível por sua importância na formação das capacidades básicas do indivíduo, na transmissão dos conhecimentos fundamentais e por seu significado para a vida produtiva.

Com o objetivo de resolver as necessidades de equipamento e reabilitaçáo do espaço físico com que opera o sistema educativo nacional, 
em 1990 criou-se o Programa de Solidariedade para uma Escola Digna, mecanismo que incorpora os setores social e privado às novas formas de trabalho comunitário.

Em sua primeira fase, as açóes do Programa são orientadas para resolver as necessidades de reabilitaçáo e manutençáo das escolas de educaçáo básica (pré-primária e de primeiro grau), tornando-se extensivo a outros níveis educativos em uma segunda etapa.

Autoridades, professores, pais de família, alunos e algumas associaçōes de classe - como de engenheiros e arquitetos - incorporaramse com entusiasmo aos trabalhos de reparação e manutenção das instalaçóes elétricas, hidráulicas e sanitárias, assim como do mobiliário; além dos de reflorestamento, pintura e limpeza das escolas.

A evasáo escolar é freqüente entre as crianças indígenas, camponesas e de famílias de baixa renda das cidades. Deve-se esse procedimento ao fato de precisarem participar do trabalho no campo, com seus pais, o mesmo ocorrendo nas cidades, onde participam da chamada economia subterrânea ou informal, realizando atividades que lhes permitem levar dinheiro para casa.

O Solidariedade esforça-se para criar condiçōes de estudo dignas que transcendam as aulas nas escolas e cheguem às casas das crianças de famílias com poucos recursos para, conjuntamente com seus pais, dar aos escolares o apoio básico de que necessitam. Isso se faz com amplo enfoque, compreendendo ajuda econômica, alimentação, cuidado com a saúde, formação de hábitos de higiene e nutrição, e participação da criança em atividades na comunidade escolar.

O programa Crianfas em Solidariedade tenta se opor à limitaçáo econômica das famílias, que impede os menores de continuar seus estudos. Para isso, através dos Comitês de Solidariedade, seleciona e propóese as crianças a serem beneficiadas com estímulos econômicos, serviços médicos e despesas básicas que propiciem concluir sua educação primária em condiçóes mais adequadas.

O Programa teve seu início em 1991, nas 17 entidades federativas que registram os mais baixos índices de eficiência final na educação primária, assim como nos núcleos de população com elevado grau de marginalização social. Em 1992 o Programa atenderá aos 31 estados da República e ao Distrito Federal.

Através do Programa Nacional de Apoio ao Servifo Social, o Solidariedade tenta fazer com que os egressos de instituiçóes de educação 
superior e nível técnico vinculem-se estreitamente à sua comunidade, através de açóes solidárias relacionadas à sua formaçăo. Destacam-se campanhas de alfabetizaçáo, fomento à saúde, melhoria urbana, saneamento e proteção ambiental, habitação digna e capacitação para o trabalho.

Prioridade do Solidariedade é assegurar aos mexicanos acesso aos alimentos em condiçōes adequadas de nutrição, qualidade e preço. A alimentação é indispensável para a formaçăo sadia dos indivíduos e o desenvolvimento de suas capacidades, especialmente entre as crianças.

O Programa participa do mercado de produtos básicos em zonas onde existe desnutrição, e que não são atendidas pelo comércio privado, para distribuir e regularizar oferta de alimentos indispensáveis à dieta das famílias de baixa renda.

O Solidariedade promove também ampliafão dos servigos de água potápel e encanada através da construção, extensão e reparo dos sistemas correspondentes em zonas rurais e nas colônias, objetivando elevar os níveis de vida e saúde dos habitantes em situaçáo de pobreza.

Para incrementar $o$ atendimento dos serviços, combina-se $o$ aproveitamento racional da infra-estrutura instalada com a construçáo de novos sistemas e a auto-suficiência financeira dos organismos que os administram.

Em 1990 criou-se o Programa Nacional de Agrua Potdipel e Encanada em Zonas Urbanas (APA), no qual se estabeleceu novo modelo de financiamento com recursos dos governos federal, estaduais e municipais, créditos do banco de desenvolvimento e contribuiçóes e trabalho das comunidades.

A eletrificafão - em suas modalidades urbana e rural - tem ampla significação para o país por não só auxiliar a mobilidade social, como também tornar possível a realização de atividades produtivas, principalmente as orientadas para apoio à economia familiar, que não podiam ser desenvolvidas pela falta da rede elétrica.

A esse respeito, o Solidariedade se propóe a multiplicar esforços para dotar de eletrificação rural o maior número de famílias, através da soma de recursos públicos e comunitários.

Destaca-se, por seu efeito social, a eletrificação dos municípios de Chalco, Chimalhuacán e Ixtapaluca, entre outros, com atendimento de quase dois milhóes de habitantes. 
O processo de urbanizaf̧ão no México tem sido, nas últimas décadas, complexo e acelerado, sem planejamento determinado em seu conjunto. A urbanizaçáo constitui processo de transformaçáo do padrão territorial, dos assentamentos humanos, e representa base material mais eficiente para distribuir os benefícios do desenvolvimento.

O elevado crescimento populacional e os movimentos migratórios para as cidades em grande escala determinaram que, até 1988, o grau de urbanização (porcentagem da populaçăo total que vive em localidades com mais de 15.000 habitantes) chegou a 60 por cento.

A aglomeração em algumas cidades e a dispersão dos habitantes rurais em localidades isoladas dificultam a prestaçăo de serviços e implicam elevados custos para sua introduçáo, devido à ocupação irregular do solo em zonas impróprias e de difícil acesso pelas condiçōes fisiográficas (fortes declives, áreas inundáveis, solos rochosos ou muito compactos).

O Pronasol apóia, desse modo, obras de pavimentaçăo e calçamento de ruas, construçáo de meio-fio e calçadas, instalaçáo de iluminação pública, recuperação de praças e de espaços públicos de recreação.

A babitafão é o espaço vital da família, componente básico de sua integração social e elemento fundamental para seu desenvolvimento harmonioso. Construir ou reformar uma casa significa estimular a atividade econômica, gerar emprego, promover a poupança familiar e enraizar a populaçáo em seu local de origem.

Através de ação combinada com as comunidades, o Solidariedade propos como tarefa imediata a realização de obras para superar as carências e as deficiências da habitação popular.

A migraf̧ão campo-cidade, a alta concentrafắo urbana e o encarecimento da terra provocaram a formaçăo de assentamentos humanos irregulares. No final de 1988, a Comissão para a Regularizaçáo da Posse da Terra (Corett) constatou haver 1.787.800 lotes com irregularidades de construçōes urbanas em terrenos públicos e comunitários.

A regularização do solo urbano é atividade complexa que requer minuciosos estudos para chegar a soluçóes justas, dar segurança aos colonos e reconhecer os direitos dos posseiros e dos núcleos agrários atingidos. Legalizar a posse da terra é imperativo de justiça social, facilitando a introdução de serviços públicos e a obtenção de créditos para construçáo ou melhoria das casas.

O título de propriedade proporciona a cada família a ce:teza de 


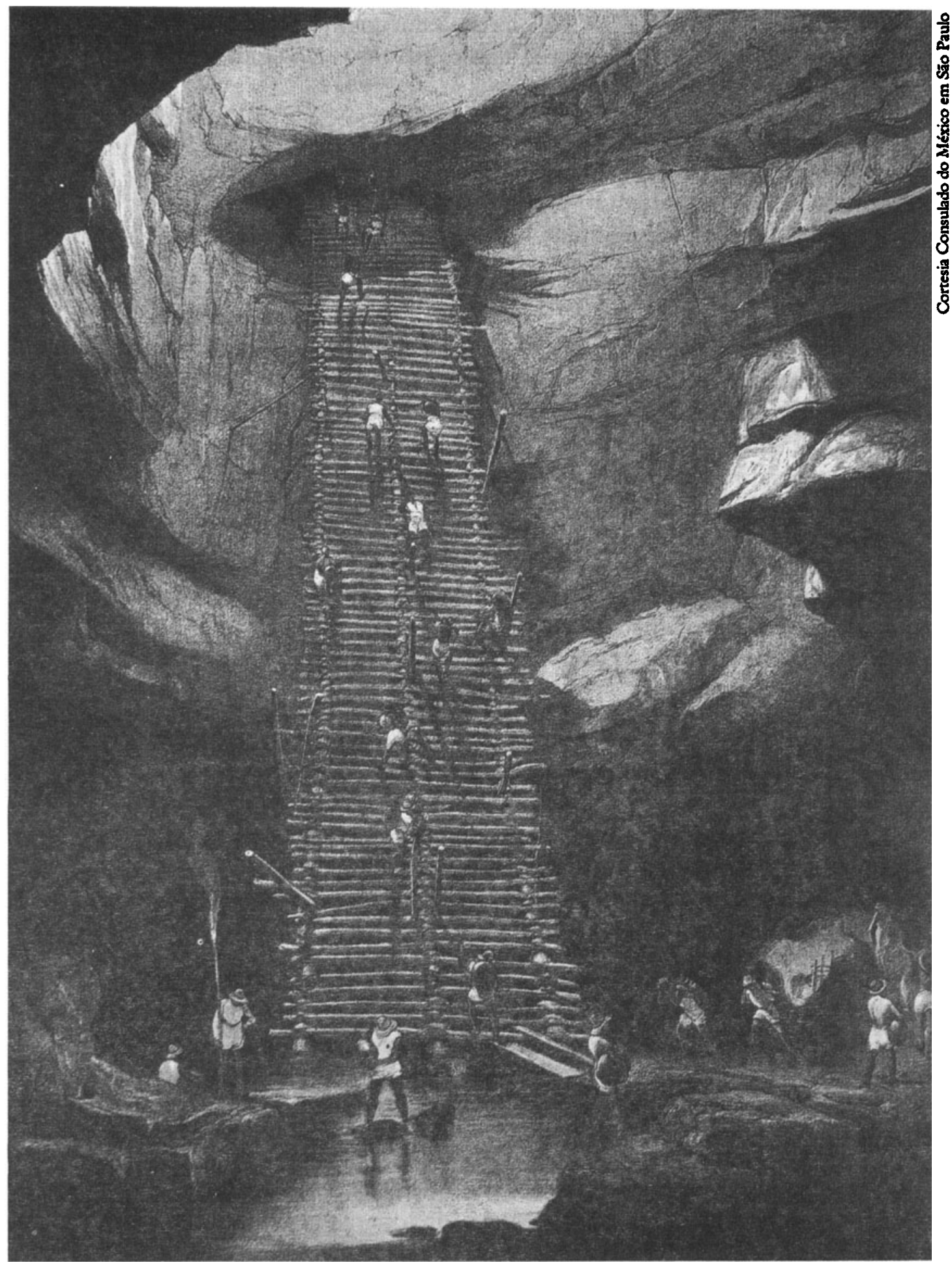

A gruta de Bolonchén, no México. Desenho de F. Catbeverwood. 
legalidade quanto ao uso e à posse da terra, assim como a segurança de que ninguém lhe poderá tirar o patrimônio construído com tanto esforço e por longo tempo.

$\mathrm{Na}$ execução dessas açōes, a população participa do levantamento da cartografia necessária para determinar áreas e limites das construçóes; - Programa agiliza a escrituraçáo e facilita às famílias mais pobres terem a tranqüilidade de que o patrimônio que criaram para seus filhos thes pertença legalmente.

Para se ter idéia da magnitude do esforço que o Programa realiza, basta assinalar que no período de 1989-1990 a Corett expediu quase um milhāo de escrituras junto aos governos dos Estados. Em 1991 essa Comissáo pretende regularizar 205.000 construçóes, as quais, somadas às 245.000 calculadas como tendo sido regularizadas pelos governos estaduais, permitirá que em apenas um triênio se resolva $60 \%$ da deficiência existente até 1988.

Os meios de transporte terrestres representam a possibilidade de intercâmbio cultural e comercial entre as regiōes, favorecendo a introduçáo de serviços, estimulando a atividade econômica e facilitando os deslocamentos aos centros educativos e de saúde.

O Pronasol participa da construção, recuperação e conservação de estradas e vias rurais, a fim de continuar com a integraçăo das comunidades isoladas do desenvolvimento nacional.

A mulher mexicana sempre interferiu nos acontecimentos nacionais, porém sua participaçáo foi limitada e pouco reconhecida. Fatores de ordem estrutural e cultural inibem o pleno exercício de seus direitos, apesar de suas grandes responsabilidades.

De acordo com levantamentos preliminares do XI Censo Nacional de População e Habitação 1990, o México conta com mais de 41,2 milhóes de mulheres ( $50,8 \%$ do total da populaçáo). Um conglomerado humano dessa magnitude representa imperativo de abertura à participação social, o acesso aos processos produtivos e ao bem-estar integral da mulher.

O programa Mulheres em Solidariedade estimula a organizaçáo de grupos com o fim de executar projetos produtivos e de bem-estar definidos pelas participantes em sua própria comunidade, de acordo com as vantagens oferecidas pelas condiçōes de sua localidade. Destacam-se as açóes em oficinas de costura, calçado, artesanato, moendas de nixtamal, casas de massas, hortas, pomares e granjas comunitárias. 
Além de obterem receitas adicionais para suas famílias, organizamse também para melhorar suas casas, participam da introdução de serviços básicos em importantes campanhas de saúde e prevenção de doenças.

\section{Programas de apoio produtivo}

O Pronasol apóia e promove projetos das organizaçóes sociais com potencial produtivo que contribuam para o bem-estar familiar, comunitário e regional.

Entre os projetos produtivos mais importantes, destacam-se os de apoio a cafeicultores, a pescadores ribeirinhos e a pequena mineração.

Apoio a cafeicultores. No cultivo do café trabalham aproximadamente 200.000 produtores, dos quais $60 \%$ são indígenas. Em dezembro de 1989, uma geada prejudicou gravemente as plantaçóes do grão em Hidalgo, San Luis Potosí, Puebla e Veracruz. Nesses estados têm sido realizadas açóes de rejuvenescimento e renovaçáo de cafezais, com apoio para a semeadura de cultivos básicos e constituição de 919 Comitês de Solidariedade.

Posteriormente, ampliou-se o atendimento para oito localidades com vocação produtora do grão, empreendendo-se açōes de apoio à produção, fertilizaçăo, corte, armazenamento e comercialização.

O prazo para pagamento dos financiamentos compreende períodos de um a três anos; também nas regiōes não afetadas pela geada, haverá estímulos para a fertilizaçáo e o corte.

Para o ciclo agrícola 1991-1992, serão incentivadas as atividades de armazenamento e comercialização, através das associaçōes de comunidades e das organizaçōes regionais. Serão constituídos fundos restituíveis ao término da comercialização do grão. $O$ retorno dos investimentos será mantido na comunidade, decidindo-se o melhor destino a the ser dado em matéria de apoio aos produtores de café.

Apoio a pescadores ribeirinhos. Como fonte geradora de empregos, receitas e produtos alimentícios de baixo custo, a pesca ribeirinha e a aqüicultura constituem alternativas viáveis ante a baixa rentabilidade $\mathbf{e}$ a sinistralidade de outras atividades agrícolas; contribuem também para melhorar a qualidade da alimentaçáo das comunidades rurais.

Incentiva-se o cultivo de espécies de consumo popular, como o bagre, a carpa, assim como a captura de crustáceos, moluscos, cação e 
algas. Da mesma forma, implementaram-se importantes programas de desenvolvimento pesqueiro e de piscicultura em Michoacán e Yucatán. Em Michoacán o Programa se orientou para a produção aqüícola, com a construção de seis fileteadoras rurais na margem da represa de Infiernillos e dez tanques rústicos; além disso, foi iniciada a produção de microalgas para a alimentaçáo de peixes, elaborando-se estudos para otimizar a cultura de certas variedades de peixes.

Em Yucatán incrementa-se a aqüicultura e a pesca, em Campeche e em Veracruz apóiam-se projetos para dotar pescadores e piscicultores com baixa renda, de embarcaçóes e equipamentos.

Apoio à pequena minerafão. Os graves problemas de operação e desenvolvimento enfrentados por pequenas organizaçōes mineradoras não lhes permitem adquirir equipamento e material para melhorar o rendimento da extraçáo de minérios. Em resposta a essa demanda, o Pronasol contribuiu, a partir de 1989 , com a exploraçáo e a comercialização de recursos: mármore em Durango e Coahuila; pedreira em Tlaxcala; ônix em Zacatecas; caulim em Veracruz; turquesa em Sonora, e quartzo em Jalisco.

\section{Programas para comunidades indígenas}

Mais de cinco milhóes de indígenas vivem no meio rural e retiram sua subsistência das atividades primárias. Suas localidades sofrem elevada marginalização; nas comunidades indígenas, os indicadores sociais da pobreza, como analfabetismo e baixa expectativa de vida elevam-se até duplicar, em alguns casos, em relaçáo às médias nacionais.

Os problemas de justiça com as etnias concentram-se principalmente nos campos penal e agrário. A indefiniçáo legal da propriedade agrária se traduz em insegurança e tensão, que impossibilitam a melhoria das condições de produçáo e produtividade.

O Programa Nacional de Solidariedade atende a esse grupo prioritário através da ampliaçáo do atendimento de saúde, com novos centros e unidades médicas; em zonas de difícil acesso, aperfeiçoou-se o sistema de abastecimento de produtos básicos, com feiras rurais e leiterias; introduziram-se os serviços de água potável e eletrificação, e trabalhouse com as comunidades para abrir, ampliar e consertar estradas.

O Instituto Nacional Indigenista (INI) realiza açóes em quatro áreas fundamentais: desenvolvimento econômico, bem-estar social, justiça e fomento ao patrimônio cultural. 
Fundos regionais para o desenvolvimento dos popos indígenas. Com o objetivo de reverter o atraso econômico que prevalece entre os povos indígenas criou-se, em março de 1990, o Fundo de Solidariedade para as Comunidades Indígenas. Sua finalidade é incentivar projetos produtivos rentáveis, que contribuam para gerar mais empregos remunerados e fortaleçam os processos organizativos das comunidades.

O Fundo opera de maneira descentralizada, pois em cada regiăo indígena definida como área de ação dos Centros Coordenadores Indigenistas se estabelece um Fundo Regional de Comunidades Indígenas. Atualmente o INI opera 91 desses centros, em igual número de regiōes indígenas localizadas em 22 estados do país.

Cada fundo é criado com uma contribuiçăo inicial de $\mathbf{5 0 0}$ milhóes de pesos, que poderá ser menor ou maior, de acordo com características próprias da região, capacidade de execução das organizaçōes e conjunto de projetos propostos e aprovados. Esses se orientam para melhorar a eficiência das atividades primárias, aproveitando racionalmente os recursos locais com a articulação das atividades agrícola, pecuária, florestal, agroindustrial e artesanal.

O Programa deixa nas mãos das organizaçóes indígenas a administração dos fundos. Essa nova estratégia considera os indígenas como os sujeitos ativos de seu desenvolvimento.

\section{Programas para os bóias-frias}

No México existem aproximadamente cinco milhóes de bóias-frias que, em sua maioria, trabalham no noroeste do país, nos vales de Hermosillo, em Sonora; Culiacán, El Fuerte e Los Mochis, em Sinaloa; e San Quintín, na Baixa Califórnia. Também trabalham em Veracruz, Morelos e Tabasco. Grande parte dos bóias-frias são indígenas empregados conforme os ciclos produtivos, fato que os desenraíza de seu lugar de origem e os faz e sofrer as limitaçóes de um emigrante pobre. Suas receitas são geralmente inferiores ao salário mínimo, têm excessivas jornadas de trabalho e sofrem de desnutriçāo e diversas doenças. Isso é ainda mais grave se for considerado que aproximadamente $30 \%$ desses trabalhadores são mulheres vivendo em condiçōes insalubres, cujos filhos não têm acesso à educação.

O Programa tem por finalidade estimular amplo acordo interinstitucional e social para melhorar as condiçōes de vida desses trabalhadores do campo, aumentando sua produtividade.

O Programa começou em 1990, no Vale de Culiacán, com ações 
concretas de melhoria do nível de vida, com a participação de instituiçōes federais e estaduais. Com a colaboração da Associaçăo dos Agricultores do Rio Culiacán e dos próprios trabalhadores rurais, foram empreendidas açóes de saúde, instalados consultórios médicos e organizadas jornadas de vacinação e erradicação de parasitas. Em matéria de educação, realizaram-se cursos de alfabetizaçăo e educaçáo para adultos e estabeleceram-se cursos de pré-escola e primário para os filhos dessas famílias. Da mesma forma, foram empreendidas açōes de apoio nutricional e abastecimento, melhoria da habitaçăo, rede sanitária e construção de redes de água potável.

\section{Fundos de Solidariedade}

\section{Fundos de Solidariedade para a produfáo}

O Pronasol incorpora, através do Fundo de Solidariedade para a Produção, a população rural marginalizada da cobertura bancária. Com a figura do crédito à palavra, proporciona-lhes recursos para satisfazer suas necessidades de autoconsumo e incorpora-os em melhor posiçáo ao desenvolvimento produtivo do país.

O Programa iniciou sua operação com uma cobertura de 1,2 milhóes de hectares, trabalhados por $\mathbf{2 6 9 . 0 0 0}$ camponeses. As expectativas criadas permitiram atender a mais de 648.000 agricultores de 1.413 municípios, que representam 64,3\% do total do país. Expandindo a ação de produtores, a superfície de cultivo transitório habilitada subiu para 1,9 milhóes de hectares. Os camponeses decidiram o tipo de cultivo que deveria ser estabelecido: $90 \%$ destinou-se à semeadura de feijăo e milho, alimentos de consumo generalizado e imprescindivel na dieta do povo mexicano.

Com a implementação do Fundo conta-se com novo impulso para mobilizar o potencial transformador dos minifundistas e produtores de terras de cultivo transitório, sem água suficiente, com baixa produtividade e elevada sinistralidade.

A administração municipal tem a responsabilidade de controlar e distribuir os recursos, e colabora com a integração e depuração do padráo dos produtores. Em cada município é criado um Comitê de Validaçáo e Acompanhamento, formado pelas autoridades da câmara municipal e pelos representantes dos camponeses; os subsídios são entregues em dinheiro, não são cobrados juros, e devem retornar ao final da comercialização. $O$ dinheiro recuperado é aplicado em obras e açōes de 
bem-estar comunitário definidas pela assembléia do Comitê de Solidariedade, do qual participam os camponeses. Por norma, em cada local ou comunidade é publicada a relaçáo dos camponeses apoiados e a lista dos retornos.

\section{Fundos Municipais de Solidariedade}

Em 1983, os municípios foram autorizados a prestarem e usufruírem dos serviços de água potável, iluminação pública, limpeza, mercados, cemitérios, matadouros, ruas, parques e jardins, segurança pública, trânsito, administraçáo do imposto predial e assentamento do solo em suas jurisdiçōes territoriais.

Com essas reformas fortaleceram-se as câmaras municipais, com funçóes e recursos para ampliar sua capacidade de resposta às demandas de suas populaçáo. Todavia, persistem situaçóes de pobreza e atraso em serviços públicos, as quais contribuem para o desequilíbrio entre as regiôes e favorecem a emigraçáo para os centros urbanos.

Em 1990 foram criados os Fundos Municipais de Solidariedade, para transferir recursos adicionais aos municípios mais pobres do país e fortalecer sua capacidade financeira e de gestão ante as necessidades de seus habitantes.

Em alguns casos as contribuiçóes movimentadas nos Fundos são equivalentes à totalidade dos recursos orçamentários arrecadados pela fazenda municipal, o que contribui para eliminar atrasos e melhorar, de modo significativo e imediato, a qualidade de vida das comunidades participantes.

As obras executadas podem ser agrupadas em três categorias: as de caráter social, que incluem a construção e reparaçăo de sistemas de água potável e drenagem; escolas; instalaçóes esportivas; centros de saúde; ruas; parques e jardins. As de sentido produtivo, como perfuração de poços para irrigaçáo; construção e conserto de canais; margens; unidades pecuárias; tanques rústicos; nivelação de solos; desempedramento e empacotamento de produtos agrícolas. As de infra-estrutura, como construção e recuperação de vias rurais, pontes e centros de armazenamento e eletrificação de povoados rurais e colônias.

A operação desses Fundos está a cargo dos Conselhos Municipais de Solidariedade e dos Comitês Municipais de Solidariedade, nos quais, de maneira democrática, a comunidade decide sobre as obras de benefício comum a serem realizadas para melhorar o nível de bem-estar da coletividade. 


\section{Programas de desenvolvimento regional}

Os programas especiais de desenvolvimento regional abrangem mais de dois estados ou municípios e fazem parte da estratégia de combate à pobreza, como complemento do processo social e produtivo realizado no espaço comunitário e municipal. Assim se consegue que o processo impulsionado em uma comunidade seja vinculado ao dos municípios e destes ao da localidade e da região. Dessa forma, não só são resolvidos problemas comuns a vários estados ou municípios, como também consolidadas as bases do desenvolvimento integral.

\section{Um balanço final}

A estratégia de combate à pobreza baseia-se em nova participação das comunidades e em colaboraçáo dinâmica entre sociedade e governo, fazendo parte da reforma do Estado e da modernização nacional.

Apoiado nessa experiência de trabalho democrático, o Pronasol contribui para fortalecer a capacidade de resposta do país ante os desafios a lhe serem impostos pelos novos blocos que estáo se formando no mundo.

A experiência da história nos mostra que a luta dos mexicanos pela justiça social e pela democracia tem sido uma constante. $O$ projeto nacional vigente na Constituiçáo dá força a nossas instituiçóes para modernizar sua relação com a sociedade e as formas em que esta se organiza e participa de todos os aspectos da vida do país. Por isso, o Solidariedade respeita a pluralidade dos mexicanos, deposita nas comunidades confiança, recursos e oportunidades de colaborar para a elevação de seu bem-estar.

O Solidariedade está aberto a todos os mexicanos, independentemente de sua posição ideológica ou militância política. O Governo da República está à disposiçáo de todo o povo, porque, se nos mantivermos unidos no essencial, com base no que nos identifica, com nosso nacionalismo e nossos valores culturais, o princípio da maior transcendência do Solidariedade será partilhado plenamente.

Um dos primeiros atos de Governo do Presidente Carlos Salinas de Gortari foi a criação do Programa Nacional de Solidariedade (Pronasol). Em 6 de dezembro de 1988 decretou a formaçăo da Co- 
missão do Pronasol, presidida pelo próprio chefe do Executivo, da qual participam, de maneira permanente, titulares das SHCP, Secofi, Sedue (agora Secretaria de Desenvolvimento Social), SAHR, SEP, Secretaria da Saúde, do Trabalho e Previdência Social, da Reforma Agrária, da Pesca, do DDF, do IMSS, da Conasupo, do Instituto Nacional Indigenista, do Fundo Nacional para o Desenvolvimento do Artesanato, da Comissáo Nacional de Zonas Áridas e da Florestal, S.C.L. Conta ainda com um Conselho Consultivo, do qual participam, além dos titulares das entidades mencionadas, representantes de núcleos indígenas, setores social e privado, e especialistas de reconhecido prestígio no campo das ciências sociais. Recentemente esse Conselho publicou o livro Solidariedad en debate, editado por El Nacional, México, 1991, do qual se tomaram partes substanciais do texto Solidariedad en México, cujo autor é Coordenador Geral do Programa Nacional de Solidariedade. Em alguns casos, Comercio Exterior fez mudanças editoriais, resumindo parágrafos e modificando subtítulos.

\section{Notas}

1 Uma visão completa da situação indígena no México aparece no Instituto Nacional Indigenista, "Programa Nacional de Desarrollo de los Pueblos Indígenas 1991-1994", em Comercio Exterior, v. 41, n.3, México, mar. 1991, p. 304-317 (N. da R.).

2 O Presidente da República tomou a iniciativa de criar a Secretaria de Desenvolvimento Social (Sedeso) que, além de assumir parte importante das funçōes que a Sedue desempenhava, vai se encarregar da execuçāo do Pronasol.

Carlos Rojas Gutiérrez é integrante da Comissão do Programa Nacional de Solidariedade (Pronasol).

Publicado originalmente na revista Comercio Exterior, v. 42, n. 5. México, maio de 1992.

Tradução de Helena B. C. Pereira e Rena Signer. O original em espanhol - $E l$ Programa Nacional de Solidaridad: hechos e ideas en torno a um esfuerzo - encontra-se à disposição do leitor no IEA para eventual consulta. 